\title{
HER2/Neu Positive by FISH
}

National Cancer Institute

\section{Source}

National Cancer Institute. HER2/Neu Positive by FISH. NCI Thesaurus. Code C141434.

A laboratory test result indicating the presence of HER2/Neu in a tissue sample using fluorescence in situ hybridization. 